\title{
Hemorrhage in Essential Thrombocythemia or Polycythemia Vera: Epidemiology, Location, Risk Factors, and Lessons Learned from the Literature
}

\author{
Christophe Nicol $^{1}$ Karine Lacut ${ }^{2,3}$ Brigitte Pan-Petesch ${ }^{1,3}$ Eric Lippert ${ }^{4,5}$ Jean-Christophe lanotto ${ }^{1,3,5}$ \\ ${ }^{1}$ Service d'Hématologie Clinique, Institut de Cancéro-Hématologie, \\ CHRU de Brest, Bretagne, France \\ ${ }^{2}$ Département de Médecine Interne et Pneumologie, CHRU de Brest, \\ Bretagne, France \\ Address for correspondence Christophe Nicol, MD, Service \\ d'Hématologie Clinique, Institut de Cancéro-Hématologie, CHRU de \\ Brest, 29200 Bretagne, France \\ (e-mail: christophe.nicol@chu-brest.fr).
}

${ }^{3}$ GETBO, Groupe d'Etude de la Thrombose de Bretagne Occidentale, $\mathrm{CHRU}$ de Brest, Brest, Bretagne, France

${ }^{4}$ Laboratoire d'Hématologie, CHRU de Brest, Bretagne, France

${ }^{5}$ FIM, France Intergroupe des Néoplasies Myéloprolifératives, France

Thromb Haemost 2021;121:553-564.

\begin{abstract}
Keywords

- essential thrombocythemia

- polycythemia vera

- bleeding

- risk factors

- classification

Hemorrhage is a well-known complication of essential thrombocythemia (ET) and polycythemia vera (PV), but evidence-based data on its management and prevention are lacking to help inform clinicians. In this review, appropriate published data from the past 15 years regarding bleeding epidemiology, classification, location, and risk factors are presented and discussed. Research was conducted using the Medline database. The bleeding classifications were heterogeneous among the collected studies. The median incidences of bleeding and major bleeding were 4.6 and $0.79 \%$ patients/year, in ET patients and 6.5 and $1.05 \%$ patients/year in PV patients, respectively. The most frequent location was the gastrointestinal tract. Bleeding accounted for up to $13.7 \%$ of deaths, and cerebral bleeding was the main cause of lethal hemorrhage. Thirty-nine potential risk factors were analyzed at least once, but the results were discrepant. Among them, age $>60$ years, bleeding history, splenomegaly, myeloproliferative neoplasm subtype, and platelet count should deserve more attention in future studies. Among the treatments, aspirin seemed to be problematic for young patients with ET (especially CALR-mutated ET patients) and anagrelide was also identified as a bleeding inducer, especially when associated with aspirin. Future studies should analyze bleeding risk factors in more homogeneous populations and with common bleeding classifications. More tools are needed to help clinicians manage the increased risk of potentially lethal bleeding events in these diseases.
\end{abstract}

\section{Introduction}

Myeloproliferative neoplasms (MPNs) are a group of hematological malignancies individualized in the 2016 World Health Organization (WHO) classification. ${ }^{1}$ They are subdivided into two groups: chronic myeloid leukemia and Philadelphia-negative MPNs, which are further divided into essential thrombocythemia (ET), polycythemia vera (PV), primitive myelofibrosis (PMF), and prefibrotic myelofibrosis. Philadelphia-negative MPNs are characterized by the chronic proliferation of myeloid cells in bone marrow and three main clonal mutations. ${ }^{1}$ Life expectancy is reduced due to the increased rate of thrombosis and hemorrhage ${ }^{2}$ and risk of hematological transformation into acute myeloid leukemia and/or secondary myelofibrosis. ${ }^{2}$ Up to $39 \%$ of patients will suffer from arterial and/or venous thrombosis throughout received

May 26, 2020

accepted after revision

September 30, 2020

published online

November 13, 2020 (c) 2020. Thieme. All rights reserved. Georg Thieme Verlag KG,

Rüdigerstraße 14,

70469 Stuttgart, Germany
DOI https://doi.org/ 10.1055/s-0040-1720979. ISSN 0340-6245. 
the course of ET or PV. ${ }^{3,4}$ Recent guidelines focus mainly on reducing the thrombotic risk. ${ }^{5,6}$

Hemorrhages are less frequent than thrombosis in MPNs and have been found in 3 to $18 \%$ of ET and 3 to $8.1 \%$ of PV cases. ${ }^{7}$ They are mostly described as a consequence of acquired von Willebrand syndrome (AWS) or in the presence of thrombocytopenia, MPN-associated thrombopathy, and/or antithrombotic drug use. ${ }^{7,8}$ MPN studies usually focus on thrombosis and give few details about bleeding. A recent review on thrombosis and bleeding complications in MPNs underlined the lack of evidence-based data to support guidelines for the prevention and management of bleeding in MPN patients. ${ }^{9}$

In this review, data from the literature concerning bleeding epidemiology, locations, and risk factors, particularly in ET and PV patients, are presented and discussed.

\section{Methods}

\section{Data Sources and Research}

We searched English and French articles from 2004 to 2018 in the Medline database and referenced the terms myeloproliferative syndrome, myeloproliferative neoplasm, polycythemia vera, and essential thrombocythemia, in combination with either bleeding or hemorrhage. Reviews with unreleased data, prospective/retrospective observational studies, and clinical trials were collected and relevant references of these articles were also searched. Case reports, editorials, and reviews with published data were excluded.

Studies had to provide data about at least one of the following features: epidemiology of bleeding, classification of bleeding severity, location of bleeding, antithrombotic treatment at diagnosis or at the time of hemorrhage, and bleeding risk factors.

Studies were included if they reported patients with PV or ET, regardless of whether patients with other MPNs were included. In studies including patients with other MPNs, only data about ET/PV epidemiology and location are presented, if distinguishable.

All the publications included in this review concerned adult patients.

\section{Definitions and Analyses of Hemorrhagic Events}

Data on the incidence and location are presented according to "major bleeding" (MB) event or "any bleeding" event, as provided by each study. "Major hemorrhages" and "severe bleeding or hemorrhage" were considered MB events.

If the Common Terminology Criteria for Adverse Events (CTCAE) were used with no dissociation between MB and non-MB events, grade 3, 4, and 5 events were considered MB.

In most recent studies of bleeding in the general population, definitions used for bleeding severity are those of the International Society of Thrombosis and Hemostasis (ISTH), ${ }^{10,11}$ and we analyzed whether definitions observed in our review were in concordance with ISTH definitions.

According to ISTH, MB was defined in 2005 as fatal bleeding and/or symptomatic bleeding in critical areas or organs, such as intracranial, intraocular, intraspinal, retroperitoneal, intraarticular, pericardial, or intramuscular bleeding with compartment syndrome and/or bleeding causing a decline in the hemoglobin level of $2 \mathrm{~g} / \mathrm{dL}$ or more or leading to the transfusion of two or more units of whole blood or red blood cells. ${ }^{11}$ In 2015, ISTH defined clinically relevant non-MB (CRNMB) events as hemorrhages that did not meet $\mathrm{MB}$ criteria but met at least one of the following criteria: required medical intervention by a health care professional, unscheduled hospitalization, increased level of care, or a face-to-face evaluation. ${ }^{10}$

\section{Statistical Analysis}

The incidence of bleeding events was calculated and reported as both the raw incidence and incidence of bleeding per 100 patient-years. Patient-years were calculated by multiplying the median follow-up duration by the number of patients in the study. Bleeding events per 100 patientyears were calculated by dividing the raw incidence of bleeding (percentage) by the median follow-up duration.

\section{Results}

\section{Literature Search}

The study selection process is detailed in - Fig. 1. The first step led to 1,266 potentially eligible articles. After review according to the prespecified inclusion and exclusion criteria, 38 articles were selected for further analysis.

Nineteen retrospective studies provided data about MPN patients, including non-ET/PV patients. ${ }^{12-29}$ The proportion of non-ET and non-PV populations ranged from 3.2 to $33.4 \%$ in 12 studies, and this subpopulation corresponded mainly to patients with PMF. ${ }^{14,15,17,18,20-23,25-27,29}$ Raw data extracted from these studies concerning the incidence and location of bleeding are shown in - Supplementary Table S1 (available in the online version).

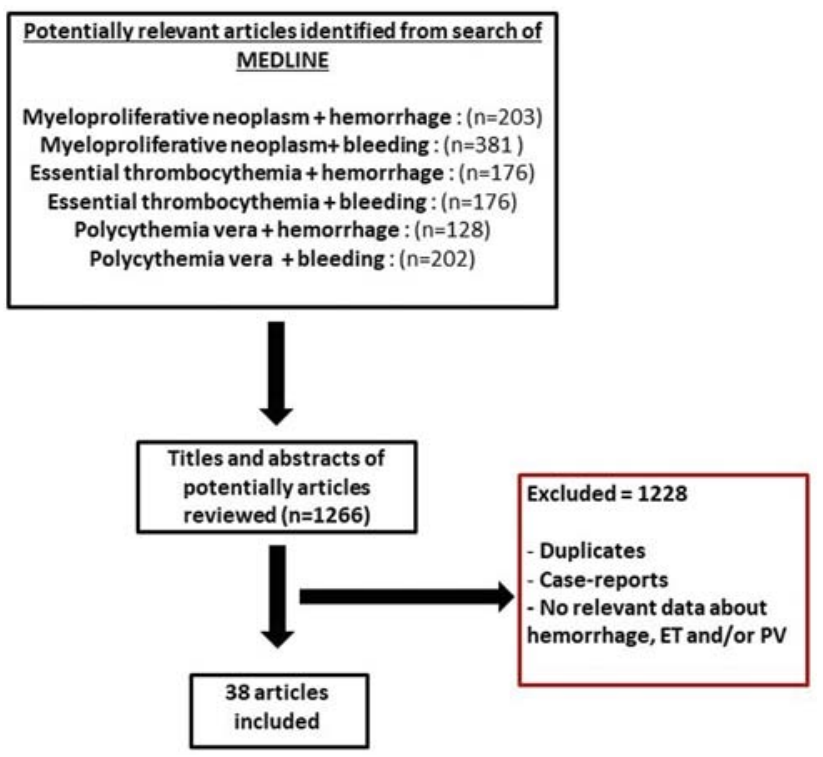

Fig. 1 Flowchart of the review of literature on hemorrhagic complications in ET and/or PV. ET, essential thrombocythemia; PV, polycythemia vera. 


\section{Incidence of Hemorrhages}

Twelve articles, including two randomized comparative studies and one phase IV study, ${ }^{30-32}$ focused on ET, with cohorts ranging from 110 to 809 patients, and a median follow-up ranging from 2.6 to 13.6 years. ${ }^{15,30-41}$

A total of 10,370 patients with ET were followed for a median time of 5 years ( - Table 1 ). Bleeding events of any severity were included with an incidence ranging from 1.39 to 6.6 per 100 patient-years. ${ }^{16,37}$ The incidence rate of MB events was 0.43 to 5.3 per 100 patient-years. ${ }^{16,28}$ The two highest incidences were reported in one study in which patients received a vitamin K antagonist (VKA $)^{42}$ and another study with less stringent MB criteria. ${ }^{16}$

Seven studies, including three randomized comparative studies, ${ }^{43-45}$ focused only on PV, with cohorts ranging from 155 to 1,638 patients, and a median follow-up ranging from 1.6 to 16.3 years. $3,43-48$

In the PV literature, a total of 5,683 patients were followed for a median time of 4.8 years ( $\boldsymbol{-}$ Table $\mathbf{2}$ ). The incidence rate of MB events ranged from 0.3 to 5.3 per 100 patient-years. Bleeding events of all types were included with an incidence ranging from 0.1 to $5.64 \%$ patients/year.

Data about the timing of bleeding occurrence after MPN diagnosis were scarce. Five studies presented either eventfree survival or cumulative incidence of bleeding at different time points. ${ }^{16,26,32-34}$ One article found that the median time of first hemorrhage occurrence was 2 years, and it was based on pooled data from several MPNs. ${ }^{17}$ Finally, another study presented a constant occurrence of bleeding over 160 months after diagnosis, contrary to thrombosis occurrence which decreased during the same period. ${ }^{23}$

\section{Heterogeneity of Hemorrhage Severity Definitions}

Several bleeding severity scales and definitions were used throughout the 38 articles (-Supplementary Fig. S1, -Supplementary Tables $\mathbf{5 2}$ and $\mathbf{5 3}$ [available in the online version]). Four studies explicitly used ISTH definitions for MB events. ${ }^{12,24,25,27}$ Sixteen articles used similar definitions

Table 1 Incidences of hemorrhages depending on their severity during the follow-up of ET patients

\begin{tabular}{|c|c|c|c|c|c|c|}
\hline Year & First author & $n$ & $\begin{array}{l}\text { Median } \\
\text { FU (y) }\end{array}$ & $\begin{array}{l}\text { Incidence of hemorrhages } \\
\text { (during follow-up } \\
\text { and } 100 \mathrm{pts} / \mathrm{y} \text { ) }\end{array}$ & $\begin{array}{l}\text { Incidence of major } \\
\text { bleedings (during follow-up } \\
\text { and } 100 \mathrm{pts} / \mathrm{y} \text { ) }\end{array}$ & $\begin{array}{l}\text { Incidence } \\
\text { of lethal } \\
\text { bleedings }\end{array}$ \\
\hline 2005 & Harrison 32 & 809 & 3.3 & - & 9.2 and $2.83 \% \mathrm{pts} / \mathrm{y}$ & $13.7 \%$ \\
\hline 2005 & Chim $^{33}$ & 231 & ND & $6.5 \%$ & - & - \\
\hline 2006 & Wolanskyj $^{34}$ & 322 & 13.6 & - & $11.9 \%$ at $10 y, 15.1 \%$ at $15 y$ & - \\
\hline 2007 & Radaelli $^{35}$ & 306 & 8 & - & 10.1 and $1.26 \% \mathrm{pts} / \mathrm{y}$ & $1.5 \%$ \\
\hline 2010 & Alvarez-Larrán ${ }^{36}$ & 300 & 5.5 & - & 5 and $0.9 \%$ pts $/ y$ & - \\
\hline 2012 & Finazzi $^{15}$ & 891 & 6.2 & - & 6.3 and $0.79 \% \mathrm{pts} / \mathrm{y}$ & - \\
\hline 2012 & Palandri ${ }^{37}$ & 565 & 7.8 & 10.8 and $1.39 \% \mathrm{pts} / \mathrm{y}$ & 3.9 and $0.5 \% \mathrm{pts} / \mathrm{y}$ & - \\
\hline 2012 & Campbell $^{38}$ & 776 & 3 & - & 3.9 and $1.3 \% \mathrm{pts} / \mathrm{y}$ & - \\
\hline 2013 & Chou $^{16}$ & 146 & 3 & 19.9 and $6.6 \% \mathrm{pts} / \mathrm{y}$ & 15.8 and $5.3 \% \mathrm{pts} / \mathrm{y}$ & - \\
\hline 2013 & Gisslinger ${ }^{41}$ & 259 & ND & $26 \%$ & $4.57 \%$ & - \\
\hline 2015 & $\operatorname{Lim}^{19}$ & 69 & 4.5 & 16.7 and $3.7 \% \mathrm{pts} / \mathrm{y}$ & - & - \\
\hline 2015 & Kander $^{17}$ & 144 & 5 & 10.4 and $2.1 \% \mathrm{pts} / \mathrm{y}$ & - & - \\
\hline 2015 & Hernández-Boluda ${ }^{42}$ & 71 & 7.7 & - & 15.5 and $2 \%$ pts/y & - \\
\hline 2015 & Duangnapasatit $^{20}$ & 83 & ND & $10.8 \%$ & - & - \\
\hline 2016 & Khan $^{21}$ & 52 & 6 & 13.5 and $2.25 \% \mathrm{pts} / \mathrm{y}$ & - & - \\
\hline 2016 & Kaifie $^{23}$ & 159 & ND & - & $3.8 \%$ & - \\
\hline 2017 & Rottenstreich $^{24}$ & 116 & ND & $51.7 \%$ & $6.9 \%$ & - \\
\hline 2016 & Alvarez-Larrán ${ }^{39}$ & 433 & 5.1 & - & 3.9 and $0.76 \% \mathrm{pts} / \mathrm{y}$ & - \\
\hline 2017 & Rumi $^{26}$ & 404 & 5 & - & 19.6 at $10 y$ & - \\
\hline 2017 & Harrison $^{40}$ & 110 & 2.6 & 5.5 and $2.11 \% \mathrm{pts} / \mathrm{y}$ & 1.82 and $0.7 \% \mathrm{pts} / \mathrm{y}$ & 3 deaths: $33.3 \%$ \\
\hline 2018 & Kamiunten $^{28}$ & 117 & 3.9 & 7.7 and $1.98 \% \mathrm{pts} / \mathrm{y}$ & 1.7 and $0.44 \% \mathrm{pts} / \mathrm{y}$ & - \\
\hline 2018 & Godfrey $^{30}$ & 358 & 6.1 & 17 and $2.8 \% \mathrm{pts} / \mathrm{y}$ & 2.8 and $0.46 \% \mathrm{pts} / \mathrm{y}$ & $5.8 \%$ \\
\hline 2018 & Birgegård $^{31}$ & 3,649 & 5 & - & $\begin{array}{l}0.89 \mathrm{pts} / \mathrm{y} \text { (anagrelide) } \\
\text { and } 0.43 \% \mathrm{pts} / \mathrm{y} \text { (other } \\
\text { cytoreductive drugs) }\end{array}$ & - \\
\hline & Median (ET) & 259 & 5.1 & 12.5 and $2.18 \% \mathrm{pts} / \mathrm{y}$ & 4.57 and $0.79 \% \mathrm{pts} / \mathrm{y}$ & $9.77 \%$ \\
\hline
\end{tabular}

Abbreviations: ET, essential thrombocythemia; FU, follow-up; pts/y, patients/year; $n$, number of patients; ND, not detailed.

Note: Year and author in italic mean that the article studied several myeloproliferative neoplasm types. Difference of population size was not considered for median value calculation. 
Table 2 Incidences of hemorrhages depending on their severity during the follow-up of PV patients

\begin{tabular}{|c|c|c|c|c|c|c|}
\hline Year & First author & $n$ & $\begin{array}{l}\text { Median } \\
\text { FU (y) }\end{array}$ & $\begin{array}{l}\text { Incidence of hemorrhages } \\
\text { (during follow-up } \\
\text { and } 100 \mathrm{pts} / \mathrm{y} \text { ) }\end{array}$ & $\begin{array}{l}\text { Incidence of major bleedings } \\
\text { (during follow-up } \\
\text { and } 100 \mathrm{pts} / \mathrm{y} \text { ) }\end{array}$ & $\begin{array}{l}\text { Incidence of } \\
\text { lethal } \\
\text { bleedings }\end{array}$ \\
\hline 2004 & Landolfi $^{43}$ & 518 & 3 & 7.1 and $2.37 \% \mathrm{pts} / \mathrm{y}$ & 0.9 and $0.3 \% \mathrm{pts} / \mathrm{y}$ & - \\
\hline 2005 & Marchioli $^{46}$ & 1,638 & 2.7 & 7.8 and $2.9 \%$ pts/y & 2.2 and $0.8 \% \mathrm{pts} / \mathrm{y}$ & $4.3 \%$ \\
\hline 2011 & Kiladjian $^{44}$ & 285 & 16.3 & 1.7 and $0.1 \% \mathrm{pts} / \mathrm{y}$ & - & - \\
\hline 2013 & Tefferi $^{3}$ & 1,545 & 6.9 & - & 4.2 and $0.61 \%$ pts/y & $1.4 \%$ \\
\hline 2013 & Chou $^{16}$ & 101 & 3 & 24 and $8 \%$ pts $/ y$ & 16 and $5.3 \% \mathrm{pts} / \mathrm{y}$ & - \\
\hline 2015 & Vannucchi $^{45}$ & 221 & 1.6 & - & - & - \\
\hline 2015 & Kander $^{17}$ & 118 & 5 & 15.3 and $3.1 \% \mathrm{pts} / \mathrm{y}$ & - & - \\
\hline 2015 & $\operatorname{Lim}^{19}$ & 33 & 4.5 & 15.8 and $3.5 \%$ pts/y & - & - \\
\hline 2015 & Hernández-Boluda ${ }^{42}$ & 79 & 7.7 & - & 7.7 and $1.3 \% \mathrm{pts} / \mathrm{y}$ & - \\
\hline 2015 & Duangnapasatit $^{20}$ & 68 & ND & $7.4 \%$ & & - \\
\hline 2016 & $K_{\text {Khan }}^{21}$ & 52 & 6 & 15.4 and $2.6 \% \mathrm{pts} / \mathrm{y}$ & 7.7 and $1.3 \% \mathrm{pts} / \mathrm{y}$ & - \\
\hline 2016 & Kaifie $^{23}$ & 164 & ND & - & $10.3 \%$ & - \\
\hline 2017 & Rottenstreich $^{24}$ & 57 & ND & $36.8 \%$ & $5.3 \%$ & - \\
\hline 2017 & Yesilova $^{47}$ & 155 & 5.5 & 31 and $5.64 \% \mathrm{pts} / \mathrm{y}$ & 7.7 and $1.4 \% \mathrm{pts} / \mathrm{y}$ & $8 \%$ \\
\hline 2017 & Cerquozzi $^{48}$ & 587 & 9.1 & - & 4 and $0.44 \%$ pts $/ y$ & - \\
\hline \multirow[t]{2}{*}{2018} & Kamiunten $^{28}$ & 62 & 3.3 & 6.5 and $1.94 \%$ pts/y & 0 & - \\
\hline & Median (PV) & 136.5 & 4.5 & 15.3 and $2.9 \% \mathrm{pts} / \mathrm{y}$ & 6.5 and $1.05 \% \mathrm{pts} / \mathrm{y}$ & $4.3 \%$ \\
\hline
\end{tabular}

Abbreviations: FU, follow-up; pts/y, patients/year; $n$, number of patients; ND, not detailed; PV, polycythemia vera.

Note: Year and author in italic mean that the article studied several myeloproliferative neoplasm types. Difference of population size was not considered for median value calculation.

("ISTH-Like") that had some differences concerning the location, number of transfusions, and/or hemoglobin decline needed to define a MB. The WHO bleeding scale ${ }^{14,29}$ and the CTCAE classification ${ }^{17,40,49}$ included bleeding severity ranging from minor to lethal, and were both used twice. Bleeding severity definitions were unclear in 10 articles.

In most cases, either MB or every hemorrhage event was included. In that instance, bleeding was defined as either MB or minor bleeding events. Minor bleeding events were mostly defined as any bleeding event that did not fulfill MB criteria. Only one study used the concept of a CRNMB, which had a definition similar to that of the ISTH. ${ }^{10,19}$

\section{Location of Bleeding Events}

Locations of bleeding are often not described. Data from ET and PV patients were dissociated from pooled data of MPNs (-Supplementary Table S4 [available in the online version]). When specified, data concerning MB were separately analyzed, to assess these potentially life-threatening events independently from other hemorrhages. Data about lethal bleeding were rare.

In ET patients, 326 episodes of bleeding were described in 13 studies ${ }^{15,16,20,23,24,28,30,32,33,35,37,40,41}$ (- Fig. 2A). The gastrointestinal tract (GIT; 40.8\%) and the mouth, nose, and throat (MNT: $12.2 \%$ ) were the most frequent locations. Of note, $3.4 \%$ of episodes were postoperative bleeding. Two subdural and four intracranial hemorrhages were described in ET patients. ${ }^{16}$ We extracted $190 \mathrm{MB}$ episodes in ET patients $^{15,16,24,28,30,32,35,37,40,41}$ (-Fig. 2B). The GIT was again the most frequent site of bleeding (54.7\%). Only 16 fatal bleeding events were described. ${ }^{13,16,30,32,35-37,40}$ Three central nervous system (CNS) bleeding cases were individualized (18.8\%). ${ }^{13,35,40}$ Details were unavailable for the others.

In PV patients, seven studies reported the location of 157 bleeding episodes in a PV population $16,20,23,24,28,43,47$ (-Fig. 2C). The most frequent location was the GIT, found in $35.7 \%$ of cases. MNT and mucocutaneous (without precision) locations of bleeding were frequent, both representing $17.2 \%$ of cases. Only one study described CNS bleeding locations, with four subdural and three intracranial hemorrhages. ${ }^{16}$ The location of MB was rarely available in PV patients. Three articles analyzed $25 \mathrm{MB}$ events, mainly concerning the GIT (48\%) and the CNS (44\%) (- Fig. 2D).$^{16,24,43}$ Twenty-one lethal bleeding events of PV patients were individualized in this review. ${ }^{3,13,16,17,43,45-47}$ Locations were the CNS in four cases (19\%), the GIT in one $(4.8 \%)^{43,45,46}$, "other" in five cases (23.8\%), ${ }^{46}$ and undetailed in all other cases.

In total, among the 37 lethal events identified, only eight (21.6\%) were described, and seven (18.9\%) were CNS bleeding. Hemorrhages represented a limited proportion of death, accounting for 1.4 to $8 \%$ for PV patients ${ }^{3,46,47}$ and 1.5 to $13.7 \%$ for ET patients. ${ }^{30,32,35}$ Most importantly, the case fatality rate of MB ranged from 3.1 to $26.7 \%$ of cases. ${ }^{3,30,32,35,37,46,47}$ In total, 20.6\% (35/170) of MB events led to death. 


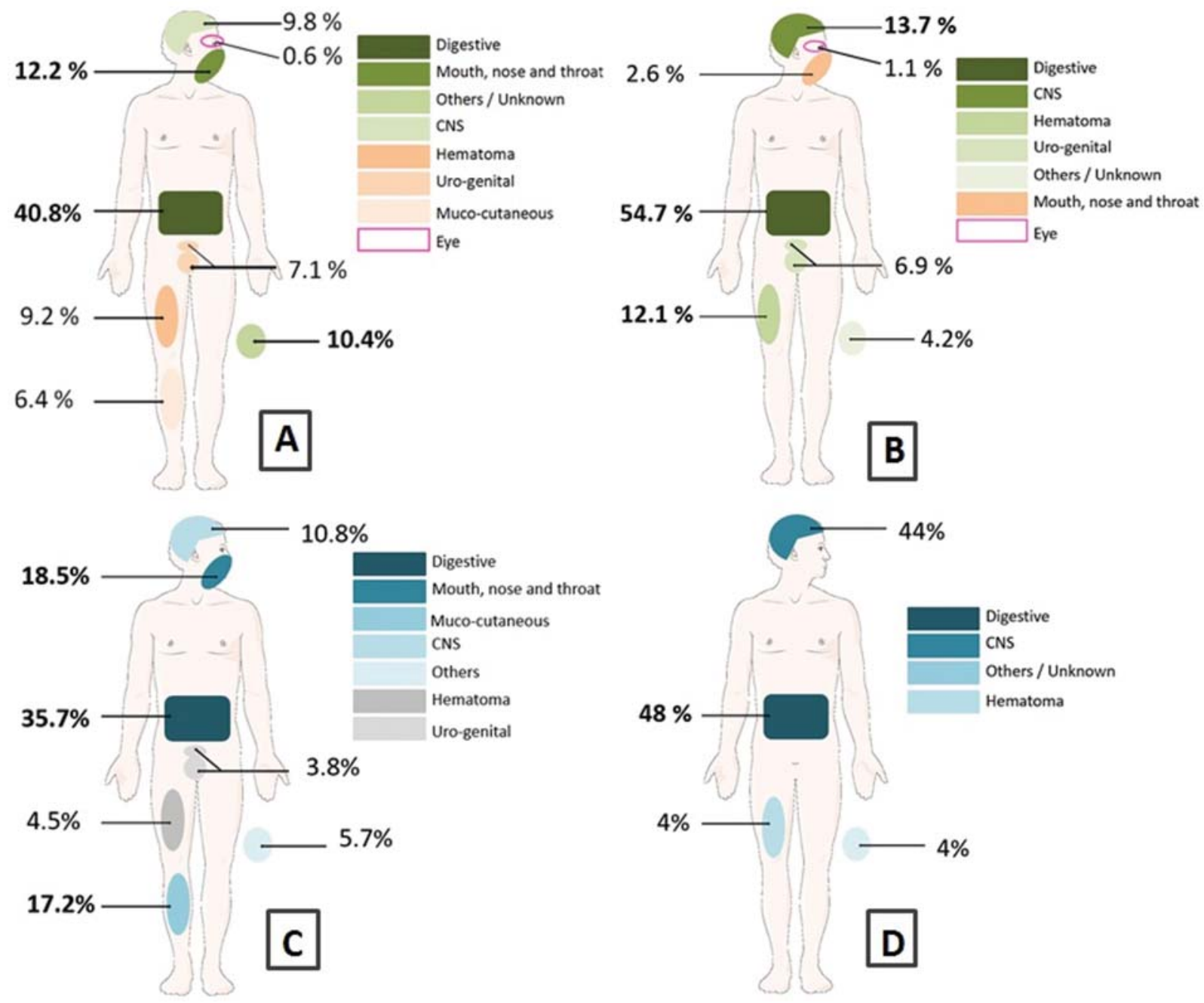

Fig. 2 Location of any bleeding and specifically major bleeding event in PV and ET patients in the literature. Eye location only concerns the posterior chamber. Serous membrane locations include the hemoperitoneum, hemothorax, and hemopericardium. (A) There were 326 bleeding episodes in ET patients in the literature. Urological (2.5\%) and gynecological (4.6\%) locations were individually recorded. "Others" contains hemarthrosis (0.9\%), "others" and "unknown" bleeding locations. Nondisplayed site is postoperative (3.4\%). (B) There were 190 major bleeding events in ET patients. Urological (3.7\%) and gynecological (3.2\%) locations were individually identified. (C) There were 157 bleeding episodes in PV patients in the literature. "Others" contains hemoptysis (1.3\%), hemarthrosis (0.6\%), and postoperative bleeding (1.9\%). (D) There were 25 major bleeding events in PV patients. ET, essential thrombocythemia; PV, polycythemia vera.

\section{Postoperative Bleeding}

Postoperative bleeding was mentioned in only six studies, and 21 episodes were described, out of 220 hemorrhages (9.6\%). ${ }^{15,20,23,24,30,41}$ Interestingly, eight were secondary to dental extraction. ${ }^{24}$ Others were not described and just labeled "postoperative" ( - Supplementary Table 55 [available in the online version]).

One study focused on this subject, with a total of $255 \mathrm{ET}$ or PV patients who underwent 311 surgeries. ${ }^{12} \mathrm{MB}$ events were defined according to the ISTH criterion. ${ }^{11}$ Major and minor bleedings events occurred in 7.3 and $2.3 \%$ of surgeries, respectively. The authors concluded that there is an increased risk of thrombosis and hemorrhages in surgeries of MPN patients.

\section{Clinical Risk Factors}

Thirty-two articles analyzed 39 potential risk factors in the MPN population. PV-focused studies presented 11 potential bleeding risk factors, whereas ET-focused studies showed 24 potential risk factors. One article analyzed 17 potential risk factors. $^{37}$

Seventeen clinical risk factors have been analyzed in the literature ( - Table 3 ). Seven were analyzed only once. The most extensively studied was age (mostly $>60$ years), but 11 studies did not lead to any consensus. ${ }^{15-18,20,21,33,36,37,43,47}$ Duration of disease, ${ }^{18,46,47}$ hypertension, ${ }^{16,31,37}$ thrombosis, ${ }^{15,17,18,23,37}$ and bleeding history ${ }^{15,16,35,37,46}$ were often considered bleeding risk factors. With the exception of hypertension, arterial cardiovascular risk factors were not bleeding risk factors. ${ }^{37}$ Interestingly, splenomegaly was associated with a significant odds ratio (OR: 2.22-7.6) in several studies. $^{16,20,23,37}$ Lastly, male gender was once found to be a bleeding risk factor with a relatively high OR of $3.74,{ }^{33}$ but there was no significant impact of gender on bleeding risk in six other analyses. ${ }^{15-17,20,36,47}$ 
Table 3 Clinical bleeding risk factors described in ET, PV, and pooled MPN studies

\begin{tabular}{|c|c|c|c|}
\hline Risk factor & Number of articles & $\begin{array}{l}p<0.05 \text { or } \\
\text { considered } \\
\text { significant } \\
\text { by the authors }\end{array}$ & Details \\
\hline Age & $11^{15-18,20,21,33,36,37,46,47}$ & $5^{16-18,21,46}$ & $\begin{array}{l}\text { Once a protective factor. }{ }^{18} \\
\text { Various thresholds used: }>40 \mathrm{y},>60 \mathrm{y}, \\
\text { median age at diagnosis or undetailed. } \\
\text { One negative test with a composite criterion } \\
\text { (history of thrombosis and/or age }>60 \mathrm{y})^{37} \\
\text { Age }>60 \text { y: HR: } 6.9(1.3-36.8)^{21}\end{array}$ \\
\hline Male gender & $7^{15-17,20,33,36,47}$ & $1^{33}$ & HR: $3.74(1.22-11.47)^{33}$ \\
\hline Ethnicity & $1^{21}$ & 1 & $\begin{array}{l}\text { Caucasian vs. non-caucasian: significant in } \\
\text { univariate analysis (HR: } 0.26[0.07-1.01] \text { ) }\end{array}$ \\
\hline Duration of disease & $3^{18,46,47}$ & 3 & - \\
\hline Thrombotic history & $5^{15,17,18,23,37}$ & $2^{18,23}$ & $\begin{array}{l}\text { Once a protective factor. }{ }^{18} \\
\text { OR }=2.71(1.36-5.4)^{23} \\
\text { One negative test with a composite criterion } \\
\text { (history of thrombosis and/or age }>60 y)^{37}\end{array}$ \\
\hline Bleeding history & $5^{15,16,35,37,46}$ & $3^{15,37,46}$ & $\begin{array}{l}\text { Significant in univariate analysis: } \mathrm{OR}=1.8 \\
(0.7-4.7))^{37} \\
\text { Significant in multivariate analysis: } \mathrm{OR}=2.35 \\
(1.11-4.98)^{15}\end{array}$ \\
\hline Cardiovascular risk factors & $1^{36}$ & 0 & ( \\
\hline Hypertension & $3^{16,31,37}$ & $1^{31}$ & Multivariate analysis: $\mathrm{OR}=1.69(1.02-2.79)^{31}$ \\
\hline Smoking & $3^{16,33,37}$ & 0 & - \\
\hline Hypercholesterolemia & $1^{37}$ & 0 & - \\
\hline Diabetes mellitus & $1^{37}$ & 0 & - \\
\hline Overweight/obesity & $1^{37}$ & 0 & - \\
\hline Clinical features & & & - \\
\hline Constitutional symptoms & $1^{20}$ & 1 & $\begin{array}{l}\text { Multivariate analysis: risk factor for PV: } \\
\mathrm{OR}=2.93(1.13-10) \\
\text { Protective factor for } \mathrm{ET}: \mathrm{OR}=0.004(0.00-0.33)\end{array}$ \\
\hline Splenomegaly & $7^{15,16,20,21,23,33,37}$ & $4^{16,20,23,37}$ & $\begin{array}{l}\text { OR: } 3.467(1.55-7.75)^{16} ; \text { OR: } 2.22(1.01-4.89)^{23} \text {; } \\
\text { OR: } 2.6(1.5-5.1)^{37} \\
\text { ET only: OR }=7.46(1.32-42.2)^{20}\end{array}$ \\
\hline Hepatomegaly & $1^{37}$ & 0 & ( \\
\hline $\begin{array}{l}\text { International PV } \\
\text { prognostic score (Tefferi } \\
\text { 2013: age, VTE, } \\
\text { leukocytes > } 15 \text { G/L) }\end{array}$ & $1^{20}$ & 0 & Low vs. intermediate \\
\hline
\end{tabular}

Abbreviations: ET, essential thrombocythemia; HR, hazard ratio; MPN, myeloproliferative neoplasm; OR, odd ratio; PV, polycythemia vera; VTE, venous thromboembolism.

\section{Biological Risk Factors}

Thirteen potential biological risk factors are shown in - Table 4.

The MPN type was studied in six articles, ${ }^{15-17,23,24,47}$ with various comparisons. Compared with ET, PV was considered by itself to be a bleeding risk factor in one out of three studies, ${ }^{16,17,23}$ and one article provided an OR (ET vs. PV: $\mathrm{OR}=0.34)^{23}$

The JAK2 mutation was analyzed 10 times but was only twice reported as a risk factor, including in one study featuring composite criteria with platelet values. ${ }^{14-17,19,24,36,37,39}$ Elevated JAK2 allele burden was found in one out of two analyses as a discriminant among JAK2-mutated PV patients. ${ }^{27}$ Two studies analyzed the impact of CALR mutations, ${ }^{17,39}$ but only one concluded there was an increased bleeding risk if CALRmutated ET patients were taking aspirin. ${ }^{39}$

Baseline platelet and leukocyte values were also frequently analyzed. The platelet-threshold $>1,000 \mathrm{G} / \mathrm{L}$ seemed consensual (three studies pro, one trending pro, and one against), ${ }^{15,16,22,31,37}$ with two hazard ratio (HR) values provided (2.3 and 2.36). ${ }^{31,37}$ Leukocyte counts were identified as risk factors in three out of 10 studies but with various thresholds. ${ }^{15-17,21,22,33,36-38,47}$ This risk seemed higher when leukocyte counts increased $(>11 \mathrm{G} / \mathrm{L}, \mathrm{HR}=1.9$ or $1.74^{15,37} ;>16 \mathrm{G} / \mathrm{L}, \mathrm{OR}=3.19^{16}$ ). 
Table 4 Biological bleeding risk factors described in ET, PV, and pooled MPN studies

\begin{tabular}{|c|c|c|c|}
\hline Risk factor & Number of articles & $\begin{array}{l}p<0.05 \text { or } \\
\text { considered } \\
\text { significant } \\
\text { by the authors }\end{array}$ & Details \\
\hline MPN disease & $6^{15-17,23,24,47}$ & $4^{15,23,24,47}$ & $\begin{array}{l}\text { PreMF vs. ET: OR }=1.74(1-3.06){ }^{15} \text { JAK2 } \\
\text { mutated ET vs. other ET and PV, }{ }^{44} \text { one post-PV } \\
\text { myelofibrosis vs. PV: OR }=2.6(1.0-6.8),{ }^{47} \text { and ET vs. } \\
P V: O R=0.34(0.13-0.91)^{23}\end{array}$ \\
\hline \multicolumn{4}{|c|}{ Baseline complete blood count } \\
\hline Platelets & $11^{15-17,20,22,31,33,36-38,47}$ & $6^{20,22,31,33,36,37}$ & $\begin{array}{l}\text { Positive thresholds tested (if detailed): }>800 \mathrm{G} / \mathrm{L}^{36} \\
\left(\mathrm{IRR}=10.6(1.7-69),{ }^{36}>1,000 \mathrm{G} / \mathrm{L}^{22,31,37}: \mathrm{HR}: 2.3\right. \\
(1.3-3.7) \text { in univariate analysis, but still significant in } \\
\text { multivariate, }{ }^{37} \mathrm{HR}: 2.36(1.42-3.93) \text { in multivariate } \\
\text { analysis, }{ }^{31}>1,200 \mathrm{G} / \mathrm{L}^{33} \\
\text { No threshold detailed: "platelets count": OR } \\
(\mathrm{PV})=1.01(1.00-1.01)^{20} \\
\text { Negative threshold tested: }>800,1,000,1,200 \text {, and } \\
1,500 \mathrm{G} / \mathrm{L},{ }^{15}>1,000 \mathrm{G} / \mathrm{L}^{16}\end{array}$ \\
\hline Leukocytes & $10^{15-17,21,22,33,36-38,47}$ & $3^{15,16,37}$ & $\begin{array}{l}\text { Positive thresholds tested: }>11 \mathrm{G} / \mathrm{L}^{15,37}: \mathrm{HR}=1.74 \\
(1.02-2.97),{ }^{15} \mathrm{HR}=1.9(1.1-3.2)^{37} ;>16 \mathrm{G} / \mathrm{L}^{16}: \\
\mathrm{OR}=3.19(1.62-6.25)^{16} \text { in multivariate analysis. } \\
\text { Negative threshold tested: }>8.7,{ }^{36}>10,{ }^{21}>11 \mathrm{G} / \mathrm{L}^{33} \\
\text { Significant for both PV and ET in univariate analysis, } \\
\text { but for PV in multivariate analysis }{ }^{33}\end{array}$ \\
\hline Hemoglobin/hematocrit & $6^{22,36-38,47}$ & $1^{22}$ & - \\
\hline Mean platelet volume & $1^{29}$ & 1 & $\begin{array}{l}\text { Positive for major bleeding ( } 10.04 \text { vs. } 8.6 \mathrm{fL} \text { ) } \\
\text { Negative for "bleeding episode of any grade" } \\
\text { Negative in multivariate analysis }\end{array}$ \\
\hline \multicolumn{4}{|c|}{ Complete blood count at bleeding } \\
\hline Platelets & $3^{23,36,38}$ & $2^{38,39}$ & $\begin{array}{l}\text { A nonlinear increase of HR once platelets }>450 \mathrm{G} / \mathrm{L}^{38} \\
\text { Negative threshold used: }>1,000 \mathrm{G} / \mathrm{L} \text { and }<100 \mathrm{G} / \mathrm{L},{ }^{23} \\
\text { and }>1,000 \mathrm{G} / \mathrm{L}+\mathrm{CALR} \text { mutation } \\
\text { Positive threshold used: }>1,000 \mathrm{G} / \mathrm{L}+J A K 2 \text { muta- } \\
\text { tion }^{39}: \text { IRR }=9.8(2.3-42.3)^{39}\end{array}$ \\
\hline Leukocytes & $2^{38,39}$ & $1^{38}$ & $\begin{array}{l}\text { A nonlinear increase of HR when leucocyte count } \\
\text { increases } 38\end{array}$ \\
\hline Hemoglobin/hematocrit & $1^{38}$ & 1 & Low hemoglobin count \\
\hline Mean platelet volume & $1^{29}$ & 1 & $\begin{array}{l}\text { Positive for major bleeding ( } 9.37 \text { vs. } 8.62 \mathrm{fL} \text { ) } \\
\text { Negative for "bleeding episode of any grade" } \\
\text { Negative in multivariate analysis }\end{array}$ \\
\hline $\begin{array}{l}\text { Acquired Willebrand } \\
\text { syndrome }\end{array}$ & $1^{24}$ & 1 & $\begin{array}{l}\text { Criteria for diagnosis: VWF:RCo }<41 \text { or } 58 \% \\
\text { (in O and non-O blood groups), VWF:RCo/VWF: } \\
\text { Ag }<0.7 \text { and negative family history of von Willebrand } \\
\text { disease }\end{array}$ \\
\hline \multicolumn{4}{|l|}{ Mutations } \\
\hline JAK2 mutation & $8^{15-18,24,36,39}$ & $2^{24,39}$ & $\begin{array}{l}\text { Positive for } J A K 2+E T,{ }^{24} \text { and } J A K 2+\text { ET plus platelets } \\
>1,000 \mathrm{G} / \mathrm{L}^{39}: \text { IRR }=9.8(2.3-42.3)^{39} \\
\text { Negative if analyzed alone }{ }^{15-18,36,37} \text { or associated } \\
\text { with antiplatelets }{ }^{36}\end{array}$ \\
\hline JAK2 allele burden & $2^{18,27}$ & $1^{27}$ & $\begin{array}{l}\text { Positive threshold: }>75 \%^{27} \text {; negative threshold: } \\
<20 \% 18\end{array}$ \\
\hline CALR mutation & $2^{17,39}$ & $1^{39}$ & $\begin{array}{l}\text { CALR+ MPN }{ }^{17} \text { and association of CALR+ET with } \\
\text { antiplatelet therapy }{ }^{39}\end{array}$ \\
\hline Albumin & $1^{16}$ & 1 & Albumin $<40 \mathrm{~g} / \mathrm{L}: \mathrm{OR}=2.37(1.18-4.79)^{16}$ \\
\hline
\end{tabular}

Abbreviations: ET, essential thrombocythemia; HR, hazard ratio; IRR, incidence rate ratio; MPN, myeloproliferative neoplasm; OR, odds ratio; preMF, prefibrotic myelofibrosis; PV, polycythemia vera; VWF:Ag, von Willebrand factor antigen; VWF:RCo, von Willebrand factor ristocetin cofactor. 
Table 5 Therapeutical bleeding risk factors described in ET, PV, and pooled MPN studies

\begin{tabular}{|c|c|c|c|}
\hline Risk factor & Number of articles & $\begin{array}{l}p<0.05 \text { or } \\
\text { considered } \\
\text { significant by } \\
\text { the authors }\end{array}$ & Details \\
\hline $\begin{array}{l}\text { Antiplatelets } \\
\text { (aspirin or } \\
\text { undetailed) }\end{array}$ & $14^{14-16,21,22,31,32,36,37,39,43,46,47}$ & $4^{15,31,32,39}$ & $\begin{array}{l}\text { Positive in association with anagrelide } 31,32: \\
\mathrm{HR}=3.55(1.96-6.44)^{31} \text { and } \mathrm{OR}=2.61(1.27-- \\
5.33), 32 \text { in CALR+ET patients }{ }^{39} \text {; "aspirin need": } \\
\text { HR: } 3.16(1.63-6.08)^{15}\end{array}$ \\
\hline Other antiplatelets & $2^{16,23}$ & 0 & $\begin{array}{l}\text { One P2Y12 inhibitor, }{ }^{23} \text { almost positive }(95 \% \mathrm{Cl} \text { : } \\
0.9979-8.0213) \\
\text { One "nonaspirin antiplatelet drug" } 16\end{array}$ \\
\hline $\begin{array}{l}\text { Antiplatelet } \\
\text { association }\end{array}$ & $1^{23}$ & 0 & Close to significance (95\% Cl: 0.9589-9.7016) \\
\hline VKA & $4^{13,23,25,42}$ & 0 & - \\
\hline DOAC & $2^{23,56}$ & 0 & $\begin{array}{l}\text { One retrospective comparison of aspirin vs. } \\
\text { DOAC }\end{array}$ \\
\hline Heparins & $1^{23}$ & 1 & Unfractionated heparin: OR: $5.64(1.83-17.34)^{23}$ \\
\hline $\begin{array}{l}\text { Antiplatelet }+ \\
\text { anticoagulation }\end{array}$ & $3^{13,25,42}$ & $1^{25}$ & One comparison with either aspirin or VKA ${ }^{25}$ \\
\hline \multicolumn{4}{|l|}{ Cytoreductive drugs } \\
\hline No details & $2^{15,22}$ & 0 & $\begin{array}{l}\text { "Need for cytoreduction"15 and "treatment } \\
\text { modalities"22 }\end{array}$ \\
\hline Hydroxyurea & $2^{16,30}$ & 0 & $\begin{array}{l}\text { Hydroxyurea vs. any other treatment, }{ }^{16} \text { and versus } \\
\text { no cytoreduction }\end{array}$ \\
\hline Anagrelide & $5^{16,18,31,32,41}$ & $3^{18,31,32}$ & $\begin{array}{l}\text { Positive studies: a phase III vs. hydroxyurea: } \\
\mathrm{OR}=2.61(1.27-5.33)^{32} \text { and a phase IV: } \mathrm{HR}=3.55 \\
(1.96-6.44)^{31} \\
\text { Negative studies: a phase III vs. hydroxyurea }{ }^{41}\end{array}$ \\
\hline Ruxolitinib & $1^{40}$ & 0 & Ruxolitinib vs. best available treatment \\
\hline
\end{tabular}

Abbreviations: DOAC, direct oral anticoagulant. ET, essential thrombocythemia; HR, hazard ratio; MPN, myeloproliferative neoplasm; OR, odd ratio; $\mathrm{PV}$, polycythemia vera; VKA, vitamin $\mathrm{K}$ antagonist.

Only one study that statistically analyzed AWS confirmed it to be a bleeding risk factor. ${ }^{24}$

\section{Antithrombotic and Cytoreductive Drugs}

Antithrombotic drugs are frequently associated with an increased risk of bleeding in the general population, ${ }^{50-55}$ thus they have been studied as potential bleeding risk factors in MPNs (- Table 5). Aspirin intake was extensively studied, with discordant results. ${ }^{14-16,21,22,31,32,36,37,39,43,46,47}$ In the only prospective trial in this field in MPN patients, the ECLAP study, PV patients were prospectively randomized into aspirin versus placebo treatments as primary thrombosis prophylaxis. ${ }^{43}$ Minor and MB events were more frequent in the aspirin group (9.1 vs. $5.3 \%$ ), but the difference was not statistically significant (risk ratio $=1.82, p=0.08$ ). Interestingly, one study showed an increased risk of hemorrhages in a young population of CALRmutated ET compared with JAK2-mutated patients. ${ }^{39}$ VKAs in MPN patients were studied less, and no statistical difference was found. 13,23,25,42 Unfractionated heparin was analyzed once, as a potent bleeding risk factor $(\mathrm{OR}=5.64)$. No other antithrombotic drugs can be clearly linked to hemorrhage in MPNs. Direct oral anticoagulants (DOACs) did not increase bleeding risk compared with aspirin in a case-control study. ${ }^{56}$
Information about antithrombotic drug use at diagnosis and at the time of hemorrhage was collected (-Supplementary Table $\mathbf{5 6}$ [available in the online version]). Information on PV and ET cases was not easily extractable from articles and reviews. At diagnosis, data were at least partially available in eight studies, ${ }^{14,17,19,23,29,32,43,46}$ for a total of 4,159 patients. Patients mostly received antiplatelet agents (57.5\%), but 3.8\% received anticoagulant drugs. Data were unavailable for $32.3 \%$ of cases. Regarding the time of the bleeding episode, data were partially available in six studies, ${ }^{17,22,27,39,41,43}$ for a total of 2,089 patients. Antiplatelet agents were the major drug class used (66.2\%), whereas $6.2 \%$ received anticoagulant drugs. Data were unavailable for $13.3 \%$ of cases.

Cytoreductive drugs have been analyzed as potential bleeding risk factors (-Table 5). Hydroxyurea is the most used cytoreductive drug. It has never been identified as a bleeding risk drug. Prospectively compared with hydroxyurea, anagrelide increased bleeding risk. ${ }^{32,41}$ Retrospectively, anagrelide in combination with low-dose aspirin seemed to increase bleeding risk compared with anagrelide alone. ${ }^{31}$ Ruxolitinib did not increase bleeding risk in a prospective study with a follow-up of 1 year. ${ }^{40}$ No data are available for pipobroman, interferon, or busulfan. 


\section{Discussion}

The most recent reviews on bleeding of MPN patients present a prevalence at diagnosis and an incidence during follow-up of 7.3 and $9 \%$ in ET and 6.9 and $8 \%$ in PV, respectively. ${ }^{9,57,58}$ Thrombotic complications remain more frequent in this population (up to $39 \%$ of patients ${ }^{3,4}$ ) compared with the general population, but hemorrhagic risk should not be underestimated due to the high rate of morbidity/mortality. Particularly, the case fatality rate from MBs of 20.6\% (35/170 events) in ET and $\mathrm{PV}$ patients must be underscored. In comparison, results from a recent meta-analysis in cancer patients treated with anticoagulant drugs found a case fatality rate of MBs of $8.9 \%$ (95 confidence interval: $3.5-21.1 \%) .{ }^{59}$ This may explain why MPN patients with hemorrhage have a lower overall survival than patients without hemorrhage. ${ }^{16}$

Currently, management of PV and ET patients is based on European Leukemia Network (ELN) criteria for thrombotic risk evaluation (age over 60 years and/or history of thrombosis). Interestingly, patients with platelet counts over $1,500 \mathrm{G} / \mathrm{L}$ are also considered high-risk patients, because of increased bleeding risk. There is no specific score of hemorrhage in MPNs.

Studies and cohorts are difficult to compare because of the heterogeneity of bleeding classifications (ISTH, CTCAE, WHO, etc.) and populations (multiple MPNs). This heterogeneity was noted in a 2017 review on ET patients, ${ }^{60}$ and it remained true in 2019 for both ET and PV patients. Only half of the studies used adapted ISTH definitions or similar definitions for MB. The CRNMB definition was published in 2015, but only one study used it. ${ }^{10,19}$ Regardless, minor bleedings events and CRNMB were mostly merged and reported as a unique entity, even in recent studies. In our opinion CRNMB is of interest. Indeed, it is associated with an increased risk of morbidity, whereas MB is associated with potential mortality.

Thirty-nine potential risk factors were analyzed at least once, but the results were contradictive. Among them, age $>60$ years, bleeding history, splenomegaly, MPN subtype, and platelet count could deserve more attention in future studies.

Among the causes of increased bleeding risk in ET and PV patients, AWS was frequently cited, although it was only analyzed once as a bleeding risk factor. ${ }^{24}$ The incidence of AWS was quite high in this study (55\% in ET and 49\% in PV), ${ }^{24}$ compared with other studies (20\% in $\mathrm{TE}^{61}$ and $12 \%$ in PV patients ${ }^{62}$ ). The diagnostic criteria of AWS are not universal, and these studies used different criteria. For example, different VWF:Rco/Ag ratio thresholds of $0.6^{61,62}$ and $0.7^{24}$ were used as one of diagnostic criteria of AWS. Another explanation of the difference of incidence could be the time between ET diagnosis and AWS testing, as it was longer in the two studies with lower incidence of AWS $^{61,62}$ possibly due to more stable hematological situations. Importantly, AWS was mostly found with platelets under 1,000 $\mathrm{G} / \mathrm{L}$, and it even presents with normal platelets. ${ }^{24,61} \mathrm{~A}$ higher leukocyte count was associated with more AWS in PV patients. ${ }^{62}$ The hemoglobin/hematocrit level also predicted the development of AWS in ET patients, ${ }^{24,61}$ and in PV patients in one study. ${ }^{62}$ It may be a consequence of increased blood viscosity associated with higher hematocrit ${ }^{63}$ and leukocytes, ${ }^{64}$ with qualitative abnormalities leading to high shear stress and increased proteolysis, particularly of high molecular-weight multimers of VWF. ${ }^{65}$ Blood count thresholds leading to the development of AWS are probably extremely variable between patients, so AWS should be systematically assessed at diagnosis; the evaluation of AWS could be repeated during follow-up until it normalized. It could also be done when bleeding and thrombosis occur and before surgeries. Tranexamic acid could be a valid option to reduce spontaneous and provoked bleeding. ${ }^{66}$ In the end, few studies focused on this frequently cited complication of MPN, and it deserves more attention.

Among cytoreductive drugs, anagrelide probably increases bleeding risk compared with hydroxyurea, ${ }^{18,31,32}$ particularly if administered with aspirin (PT1 prospective trial), ${ }^{31}$ even though one prospective trial (ANAHYDRET) did not find any difference between hydroxyurea and anagrelide. ${ }^{41}$ Thus, anagrelide is not recommended as a first-line treatment in ET patients. ${ }^{5,6}$ Hydroxyurea was compared with no cytoreduction in only one study, with no difference in bleeding risk observed. ${ }^{30}$

On the other hand, antiplatelet drugs are the most frequent drugs used, and prescriptions are adapted to ELN recommendations. It is difficult to assess their bleeding risk as most patients take aspirin as primary or secondary prophylaxis or anticoagulants as secondary prophylaxis. As a reminder, MPN patients are mostly elderly and aspirin was prospectively found to increase bleeding risk when used for the primary prevention of cardiovascular disease of 19,114 elderly patients $(\mathrm{HR}=1.38){ }^{53}$ In PV patients, the ECLAP study reported a reduction of thrombosis incidence (nonfatal myocardial infarction, nonfatal stroke, or death from cardiovascular causes) with no significant increase of bleeding with aspirin. ${ }^{43}$ No such randomized study has been done in ET. On the other hand, a retrospective study did not show any positive impact of aspirin as primary prophylaxis on the reduction of thrombosis in lowrisk ET patients. ${ }^{36}$ Furthermore, in low-risk CALR-mutated ET, aspirin did not reduce thrombosis risk but it increased bleeding risk $(p=0.03) .{ }^{39}$ A 2017 meta-analysis reported an uncertain benefit-risk ratio of antiplatelet drugs in ET patients. ${ }^{60}$ The possible absence of impact of aspirin on thrombosis and bleeding risk may be due to an insufficient control of platelet COX-1 activity with a once-daily low dose of aspirin. ${ }^{67}$

Studies on VKAs or DOACs are also lacking in this population. Such studies have been conducted in the general population, e.g., VKAs versus placebo, ${ }^{50}$ DOACs versus VKAs, ${ }^{51,52}$ and the combination of DOAC and aspirin versus DOAC and placebo. ${ }^{68}$ All of these treatments increased bleeding risk. This was also true in a population with cancer, with a particular gastrointestinal predominance for DOACs. ${ }^{69}$ Studies about DOACs in MPN patients are required to assess their bleeding risk.

Increased risk of both thrombosis and bleeding may be chronologically dissociated. A retrospective study in a German MPN registry showed that thrombosis events occurred mostly around the time of diagnosis, and the number of events seemed to decrease with time, in contrast to bleeding incidence, which was constant over time. ${ }^{23}$ The duration of follow-up was analyzed as a bleeding risk factor in three studies, ${ }^{18,46,47}$ and bleeding-free survival seemed to continually decrease with time in another cohort of ET and PV patients. ${ }^{16}$ The ongoing FAST trial (from the French FIM group) challenges the need of 
aspirin in ET patients treated with hydroxyurea depending on the hematological response (NCT02611973). The bleeding risk of anticoagulant drugs as a time-dependent variable must be studied.

The CNS and GIT are already known as frequent sites of MB. ${ }^{70}$ Cerebral hemorrhages must be feared, as they result in the most deaths due to bleeding. For example, in 13,559 nonMPN patients followed for a median period of 2.4 years and receiving VKA for atrial nonvalvular fibrillation, 35 out of 72 (48.6\%) cerebral bleeding events were lethal. ${ }^{71}$ The GIT often bleeds and rarely kills, but it can cause unscheduled hospitalizations and blood transfusions.

Proposed bleeding management strategies in MPNs have been recently published: (1) AWS testing prior to aspirin when platelet counts are $>1,000 \times 10^{9} / \mathrm{L}$ and the consideration of testing even with modest thrombocytosis, (2) cytoreduction to a lower platelet count in the presence of AWS, (3) supportive measures such as desmopressin and von Willebrand factor concentrates in AWS, (4) empirical platelet transfusion if bleeding is suspected to be due to qualitative platelet dysfunction, and (5) collaboration with a hemophilia specialist if there are questions regarding AWS testing/management. ${ }^{9}$

To conclude, bleeding risk of ET/PV patients should not be underestimated because of the high fatality rates, even compared with bleeding fatality rates in cancer patients with anticoagulant drugs.

First, to help physicians better understand the bleeding risk of MPN patients, future studies should be more accurate and homogeneous. They could use the ISTH classification, which is reproducible, practical, and already used in anticoagulant drug trials. Each event should be classified (major, CRNMB, and possibly minor) and incidence should be expressed as \%patients/year to equalize for the number of years.

Second, future studies should be more homogeneous to better identify bleeding risk factors. Among them, age, splenomegaly, history of hemorrhage, platelet count, and MPN subtypes at diagnosis should be focused on. Cytoreductive and antithrombotic drugs did not seem to influence bleeding profiles, but they should be evaluated as time-dependent variables. Prospective studies are still needed.

Finally, provoked bleeding (trauma, surgery, etc.) is not infrequent and could be prevented or reduced, for example, by tranexamic acid. Collaborations between surgeons and hematologists need to be improved.

\section{Authors' Contributions}

C.N., J-.C.I., B.P-.P., and K.L. elaborated the study. C.N. did the PubMed analysis. C.N. and J-.C.I. wrote the manuscript. B.P-.P., K.L., and E.L. reviewed the manuscript. All the authors have validated the final version of the manuscript.

\section{Conflict of Interest}

None declared.

\section{Acknowledgments}

The authors would like to thank the French GOAL group for its precious help.

\section{References}

1 Arber DA, Orazi A, Hasserjian R, et al. The 2016 revision to the World Health Organization classification of myeloid neoplasms and acute leukemia. Blood 2016;127(20):2391-2405

2 Tefferi A, Guglielmelli P, Larson DR, et al. Long-term survival and blast transformation in molecularly annotated essential thrombocythemia, polycythemia vera, and myelofibrosis. Blood 2014; 124(16):2507-2513

3 Tefferi A, Rumi E, Finazzi G, et al. Survival and prognosis among 1545 patients with contemporary polycythemia vera: an international study. Leukemia 2013;27(09):1874-1881

4 Barbui T, Thiele J, Passamonti F, et al. Survival and disease progression in essential thrombocythemia are significantly influenced by accurate morphologic diagnosis: an international study. J Clin Oncol 2011;29(23):3179-3184

5 Mesa R, Jamieson C, Bhatia R, et al. Myeloproliferative neoplasms, version 2.2017, NCCN clinical practice guidelines in oncology. J Natl Compr Canc Netw 2016;14(12):1572-1611

6 Barbui T, Tefferi A, Vannucchi AM, et al. Philadelphia chromosome-negative classical myeloproliferative neoplasms: revised management recommendations from European LeukemiaNet. Leukemia 2018;32(05):1057-1069

7 Martin K. Risk factors for and management of MPN-associated bleeding and thrombosis. Curr Hematol Malig Rep 2017;12(05): 389-396

8 Appelmann I, Kreher S, Parmentier S, et al. Diagnosis, prevention, and management of bleeding episodes in Philadelphia-negative myeloproliferative neoplasms: recommendations by the Hemostasis Working Party of the German Society of Hematology and Medical Oncology (DGHO) and the Society of Thrombosis and Hemostasis Research (GTH). Ann Hematol 2016;95(05):707-718

9 Stein BL, Martin K. From Budd-Chiari syndrome to acquired von Willebrand syndrome: thrombosis and bleeding complications in the myeloproliferative neoplasms. Blood 2019;134(22):1902-1911

10 Kaatz S, Ahmad D, Spyropoulos AC, Schulman SSubcommittee on Control of Anticoagulation. Definition of clinically relevant nonmajor bleeding in studies of anticoagulants in atrial fibrillation and venous thromboembolic disease in non-surgical patients: communication from the SSC of the ISTH. J Thromb Haemost 2015;13(11):2119-2126

11 Schulman S, Kearon CSubcommittee on Control of Anticoagulation of the Scientific and Standardization Committee of the International Society on Thrombosis and Haemostasis. Definition of major bleeding in clinical investigations of antihemostatic medicinal products in non-surgical patients. J Thromb Haemost 2005;3(04):692-694

12 Ruggeri M, Rodeghiero F, Tosetto A, et al; Gruppo Italiano Malattie Ematologiche dell'Adulto (GIMEMA) Chronic Myeloproliferative Diseases Working Party. Postsurgery outcomes in patients with polycythemia vera and essential thrombocythemia: a retrospective survey. Blood 2008;111(02):666-671

13 De Stefano V, Za T, Rossi E, et al; GIMEMA CMD-Working Party. Recurrent thrombosis in patients with polycythemia vera and essential thrombocythemia: incidence, risk factors, and effect of treatments. Haematologica 2008;93(03):372-380

14 Bang S-M, Lee J-S, Ahn JY, et al; Korean MPN Working Party. Vascular events in Korean patients with myeloproliferative neoplasms and their relationship to JAK2 mutation. Thromb Haemost 2009; 101(03):547-551

15 Finazzi G, Carobbio A, Thiele J, et al. Incidence and risk factors for bleeding in 1104 patients with essential thrombocythemia or prefibrotic myelofibrosis diagnosed according to the 2008 WHO criteria. Leukemia 2012;26(04):716-719

16 Chou Y-S, Gau J-P, Yu Y-B, et al. Leukocytosis in polycythemia vera and splenomegaly in essential thrombocythemia are independent risk factors for hemorrhage. Eur J Haematol 2013;90(03): 228-236 
17 Kander EM, Raza S, Zhou Z, et al. Bleeding complications in BCRABL negative myeloproliferative neoplasms: prevalence, type, and risk factors in a single-center cohort. Int J Hematol 2015; 102(05):587-593

18 Borowczyk M, Wojtaszewska M, Lewandowski K, et al. The JAK2 V617F mutational status and allele burden may be related with the risk of venous thromboembolic events in patients with Philadelphia-negative myeloproliferative neoplasms. Thromb Res 2015;135(02):272-280

$19 \mathrm{Lim} \mathrm{Y,} \mathrm{Lee} \mathrm{J-O,} \mathrm{Kim} \mathrm{SH,} \mathrm{et} \mathrm{al.} \mathrm{Prediction} \mathrm{of} \mathrm{thrombotic} \mathrm{and}$ hemorrhagic events during polycythemia vera or essential thrombocythemia based on leukocyte burden. Thromb Res 2015;135(05):846-851

20 Duangnapasatit B, Rattarittamrong E, Rattanathammethee T, et al. Clinical manifestations and risk factors for complications of philadelphia chromosome-negative myeloproliferative neoplasms. Asian Pac J Cancer Prev 2015;16(12):5013-5018

21 Khan I, Shergill A, Saraf SL, et al. Outcome disparities in caucasian and non-Caucasian patients with myeloproliferative neoplasms. Clin Lymphoma Myeloma Leuk 2016;16(06):350-357

22 Andıç N, Ünübol M, Yağcı E, et al. Clinical features of 294 Turkish patients with chronic myeloproliferative neoplasms. Turk J Haematol 2016;33(03):187-195

23 Kaifie A, Kirschner M, Wolf D, et al; Study Alliance Leukemia (SAL). Bleeding, thrombosis, and anticoagulation in myeloproliferative neoplasms (MPN): analysis from the German SAL-MPN-registry. J Hematol Oncol 2016;9(01):18

24 Rottenstreich A, Kleinstern G, Krichevsky S, Varon D, Lavie D, Kalish Y. Factors related to the development of acquired von Willebrand syndrome in patients with essential thrombocythemia and polycythemia vera. Eur J Intern Med 2017;41:49-54

25 De Stefano V, Ruggeri M, Cervantes F, et al. High rate of recurrent venous thromboembolism in patients with myeloproliferative neoplasms and effect of prophylaxis with vitamin $\mathrm{K}$ antagonists. Leukemia 2016;30(10):2032-2038

26 Rumi E, Boveri E, Bellini M, et al; Associazione Italiana per la Ricerca sul Cancro Gruppo Italiano Malattie Mieloproliferative Investigators. Clinical course and outcome of essential thrombocythemia and prefibrotic myelofibrosis according to the revised WHO 2016 diagnostic criteria. Oncotarget 2017;8(60): 101735-101744

27 Bertozzi I, Bogoni G, Biagetti G, et al. Thromboses and hemorrhages are common in MPN patients with high JAK2V617F allele burden. Ann Hematol 2017;96(08):1297-1302

28 Kamiunten A, Shide K, Kameda T, et al. Thrombohemorrhagic events, disease progression, and survival in polycythemia vera and essential thrombocythemia: a retrospective survey in Miyazaki prefecture, Japan. Int J Hematol 2018;107(06):681-688

29 Krashin E, Cohen O, Pereg D, Lishner M, Leader A. Mean platelet volume and risk of thrombotic and bleeding complications in patients with Philadelphia chromosome negative myeloproliferative neoplasms. Blood Coagul Fibrinolysis 2018;29(03):288-293

30 Godfrey AL, Campbell PJ, MacLean C, et al; United Kingdom Medical Research Council Primary Thrombocythemia-1 Study United Kingdom National Cancer Research Institute Myeloproliferative Neoplasms Subgroup French Intergroup of Myeloproliferative Neoplasms the Australasian Leukaemia and Lymphoma Group. Hydroxycarbamide plus aspirin versus aspirin alone in patients with essential thrombocythemia age 40 to 59 years without high-risk features. J Clin Oncol 2018;36(34):3361-3369

31 Birgegård G, Besses C, Griesshammer M, et al. Treatment of essential thrombocythemia in Europe: a prospective long-term observational study of 3649 high-risk patients in the Evaluation of Anagrelide Efficacy and Long-term Safety study. Haematologica 2018;103(01):51-60

32 Harrison CN, Campbell PJ, Buck G, et al; United Kingdom Medical Research Council Primary Thrombocythemia 1 Study. Hydroxy- urea compared with anagrelide in high-risk essential thrombocythemia. N Engl J Med 2005;353(01):33-45

33 Chim C-S, Kwong Y-L, Lie AK-W, et al. Long-term outcome of 231 patients with essential thrombocythemia: prognostic factors for thrombosis, bleeding, myelofibrosis, and leukemia. Arch Intern Med 2005;165(22):2651-2658

34 Wolanskyj AP, Schwager SM, McClure RF, Larson DR, Tefferi A. Essential thrombocythemia beyond the first decade: life expectancy, long-term complication rates, and prognostic factors. Mayo Clin Proc 2006;81(02):159-166

35 Radaelli F, Colombi M, Calori R, et al. Analysis of risk factors predicting thrombotic and/or haemorrhagic complications in 306 patients with essential thrombocythemia. Hematol Oncol 2007; 25(03):115-120

36 Alvarez-Larrán A, Cervantes F, Pereira A, et al. Observation versus antiplatelet therapy as primary prophylaxis for thrombosis in low-risk essential thrombocythemia. Blood 2010;116(08): 1205-1210

37 Palandri F, Polverelli N, Catani L, et al. Bleeding in essential thrombocythaemia: a retrospective analysis on 565 patients. $\mathrm{Br}$ J Haematol 2012;156(02):281-284

38 Campbell PJ, MacLean C, Beer PA, et al. Correlation of blood counts with vascular complications in essential thrombocythemia: analysis of the prospective PT1 cohort. Blood 2012;120(07): 1409-1411

39 Alvarez-Larrán A, Pereira A, Guglielmelli P, et al. Antiplatelet therapy versus observation in low-risk essential thrombocythemia with a CALR mutation. Haematologica 2016;101(08): 926-931

40 Harrison CN, Mead AJ, Panchal A, et al. Ruxolitinib vs best available therapy for ET intolerant or resistant to hydroxycarbamide. Blood 2017;130(17):1889-1897

41 Gisslinger H, Gotic M, Holowiecki J, et al; ANAHYDRET Study Group. Anagrelide compared with hydroxyurea in WHO-classified essential thrombocythemia: the ANAHYDRET Study, a randomized controlled trial. Blood 2013;121(10):1720-1728

42 Hernández-Boluda JC, Arellano-Rodrigo E, Cervantes F, et al; Grupo Español de Enfermedades Mieloproliferativas Filadelfia Negativas (GEMFIN). Oral anticoagulation to prevent thrombosis recurrence in polycythemia vera and essential thrombocythemia. Ann Hematol 2015;94(06):911-918

43 Landolfi R, Marchioli R, Kutti J, et al; European Collaboration on Low-Dose Aspirin in Polycythemia Vera Investigators. Efficacy and safety of low-dose aspirin in polycythemia vera. N Engl J Med 2004;350(02):114-124

44 Kiladjian J-J, Chevret S, Dosquet C, Chomienne C, Rain J-D. Treatment of polycythemia vera with hydroxyurea and pipobroman: final results of a randomized trial initiated in 1980. J Clin Oncol 2011;29(29):3907-3913

45 Vannucchi AM, Kiladjian JJ, Griesshammer M, et al. Ruxolitinib versus standard therapy for the treatment of polycythemia vera. $\mathrm{N}$ Engl J Med 2015;372(05):426-435

46 Marchioli R, Finazzi G, Landolfi R, et al. Vascular and neoplastic risk in a large cohort of patients with polycythemia vera. J Clin Oncol 2005;23(10):2224-2232

47 Yesilova AM, Yavuzer S, Yavuzer H, et al. Analysis of thrombosis and bleeding complications in patients with polycythemia vera: a Turkish retrospective study. Int J Hematol 2017;105(01):70-78

48 Cerquozzi S, Barraco D, Lasho T, et al. Risk factors for arterial versus venous thrombosis in polycythemia vera: a single center experience in 587 patients. Blood Cancer J 2017;7(12):662

49 Common Terminology Criteria for Adverse Events (CTCAE). 2017;155. Available at: https://ctep.cancer.gov/protocoldevelopment/electronic_applications/docs/CTCAE_v5_Quick_Reference_ $8.5 \times 11$.pdf

50 Singer DE, Hughes RA, Gress DR, et al; Boston Area Anticoagulation Trial for Atrial Fibrillation Investigators. The effect of low- 
dose warfarin on the risk of stroke in patients with nonrheumatic atrial fibrillation. N Engl J Med 1990;323(22):1505-1511

51 Granger CB, Alexander JH, McMurray JJV, et al; ARISTOTLE Committees and Investigators. Apixaban versus warfarin in patients with atrial fibrillation. N Engl J Med 2011;365(11):981-992

52 Agnelli G, Buller HR, Cohen A, et al; AMPLIFY Investigators. Oral apixaban for the treatment of acute venous thromboembolism. N Engl J Med 2013;369(09):799-808

53 McNeil JJ, Wolfe R, Woods RL, et al; ASPREE Investigator Group. Effect of aspirin on cardiovascular events and bleeding in the healthy elderly. N Engl J Med 2018;379(16):1509-1518

54 Wallentin L, Becker RC, Budaj A, et al; PLATO Investigators. Ticagrelor versus clopidogrel in patients with acute coronary syndromes. N Engl J Med 2009;361(11):1045-1057

55 Wiviott SD, Braunwald E, McCabe CH, et al; TRITON-TIMI 38 Investigators. Prasugrel versus clopidogrel in patients with acute coronary syndromes. N Engl J Med 2007;357(20):2001-2015

56 Ianotto J-C, Couturier M-A, Galinat $\mathrm{H}$, et al. Administration of direct oral anticoagulants in patients with myeloproliferative neoplasms. Int J Hematol 2017;106(04):517-521

57 Rungjirajittranon T, Owattanapanich W, Ungprasert P, Siritanaratkul N, Ruchutrakool T. A systematic review and meta-analysis of the prevalence of thrombosis and bleeding at diagnosis of Philadelphia-negative myeloproliferative neoplasms. BMC Cancer 2019;19(01):184

58 McMahon B, Stein BL. Thrombotic and bleeding complications in classical myeloproliferative neoplasms. Semin Thromb Hemost 2013;39(01):101-111

59 Abdulla A, Davis WM, Ratnaweera N, Szefer E, Ballantyne Scott B, Lee AYY. A meta-analysis of case fatality rates of recurrent venous thromboembolism and major bleeding in patients with cancer. Thromb Haemost 2020;120(04):702-713

60 Chu DK, Hillis CM, Leong DP, Anand SS, Siegal DM. Benefits and risks of antithrombotic therapy in essential thrombocythemia: a systematic review. Ann Intern Med 2017;167(03):170-180
61 Mital A, Prejzner W, Bieniaszewska M, Hellmann A. Prevalence of acquired von Willebrand syndrome during essential thrombocythemia: a retrospective analysis of 170 consecutive patients. Pol Arch Med Wewn 2015;125(12):914-920

62 Mital A, Prejzner W, Świątkowska-Stodulska R, Hellmann A. Factors predisposing to acquired von Willebrand syndrome during the course of polycythemia vera - retrospective analysis of 142 consecutive cases. Thromb Res 2015;136(04):754-757

63 Wells RE Jr, Merrill EW. Influence of flow properties of blood upon viscosity-hematocrit relationships.J Clin Invest 1962;41:1591-1598

64 Roath S, Davenport P. Leucocyte numbers and quality: their effect on viscosity. Clin Lab Haematol 1991;13(03):255-262

65 Tiede A. Diagnosis and treatment of acquired von Willebrand syndrome. Thromb Res 2012;130(Suppl 2):S2-S6

66 Franchini M, Mannucci PM. The never ending success story of tranexamic acid in acquired bleeding. Haematologica 2020;105 (05):1201-1205

67 Rocca B, Tosetto A, Betti S, et al. A randomized double-blind trial of 3 aspirin regimens to optimize antiplatelet therapy in essential thrombocythemia. Blood 2020;136(02):171-182

68 Connolly SJ, Eikelboom JW, Bosch J, et al; COMPASS investigators. Rivaroxaban with or without aspirin in patients with stable coronary artery disease: an international, randomised, doubleblind, placebo-controlled trial. Lancet 2018;391(10117):205-218

69 Carrier M, Abou-Nassar K, Mallick R, et al; AVERT Investigators. Apixaban to prevent venous thromboembolism in patients with cancer. N Engl J Med 2019;380(08):711-719

70 Barbui T, Barosi G, Grossi A, et al. Practice guidelines for the therapy of essential thrombocythemia. A statement from the Italian Society of Hematology, the Italian Society of Experimental Hematology and the Italian Group for Bone Marrow Transplantation. Haematologica 2004;89(02):215-232

71 Fang MC, Go AS, Chang Y, et al. Death and disability from warfarinassociated intracranial and extracranial hemorrhages. Am J Med 2007;120(08):700-705 